\section{A CASE OF ACUTE BILATERAL MASTOIDITIS}

\section{BY}

HERBERT V. O'SHEA, M.D., M.Ch., D.L.O.

ASSISTANT SURGEON, METROPOLITAN EAR, NOSE, AND THROAT HOSPITAL; SENIOR SURGEON TO THE INVALID CHILDREN'S HOSPITAL, PLAISTOW ; ASSISTANT AURIST TO THE LONDON COUNTY COUNCIL

The following case of bilateral acute mastoiditis, compli cating acute fronto-maxillary sinusitis due to the Streptococcus haemolyticus, is, I think, worthy of publication because recovery ensued in spite of the fact that, in addition to the above complications, the infection spread to the base of the left lung and the wrist-joint of the same side.

\section{Case Report}

A married woman when eight months pregnant developed an ordinary cold. Being a strong, healthy person she gave little attention to this, which was considered a trivial matter ; nevertheless it left her with an irritable cough and a certain stuffiness of the nose. Three weeks later a septic spot developed on her chin; this was eventually opened and had entirely healed before labour set in. The latter was quite normal, and in due course the patient left the nursing home.

Almost from the beginning the patient complained of faceache on the left side; this grew worse and gradually spread until the entire left half of the face became very tender and could not bear pressure. The temperature began to rise at night, and the cough became more troublesome. On January 16th, 1934, three weeks after the confinement, I was asked to see the patient.

\section{Examination}

Pus was coming from the left frontal and maxillary sinuses. The middle and inferior turbinal bones on the same side were swollen and inflamed. Acute inflammation of both sinuses was diagnosed, and an exploratory puncture of the left maxillary antrum was made under nitrous oxide anaesthesia. I found the sinus full of thick, foul-smelling pus. I ordered menthol inhalations and hot fomentations for the frontal condition, and when $I$ saw the patient two days later the pain and tenderness had considerably decreased. I again washed out the antrum, which now contained thin, watery, bloodstained pus.

\section{Operation ON Right EAR}

The patient complained of earache on the opposite sidenamely, the right. Inspection of the drum showed attic suppuration. The membrane was inflamed and bulging in the upper part, while it was more or less normal in the lower. Paracentesis was performed, and the patient was removed to a nursing home, as there was marked tenderness over the mastoid tip and I anticipated an extension of the disease into the bone itself. This proved to be correct, for the next morning the skin behind the ear was red and oedematous and exquisitely tender.

A conservative mastoid operation was performed. The bone was very thick, and contained abnormally. large cells full of pus. I found it necessary to expose a large portion of the dura, the lateral sinus from well behind the genu, and the balb. The posterior wall of the external auditory canal was removed down to the bridge, leaving the latter structure. The post-aural incision was closed, and the cavity drained through the meatus. At the same time $I$ did an endonasal antrostomy. Some of the pus from both cavities was collected and sent for a pathological examination.

The following day, January 22nd, the condition of the right ear had considerably improved, but I was informed that the patient had had no sleep owing to the pain which had suddenly developed during the night in the left ear. This necessitated a hypodermic injection of morphine. Examination of the ear revealed acute attic suppuration. The appearances were exactly similar to those seen in the first instance when the disease started in the right ear.
It was then that $I$ received the following report from the pathologist.

\section{Examination of PUS from Antrum}

The specimen was much admixed with blood, but direct films showed the presence of some pus cells (polymorphs) in addition to the blood cells, and a number of Gram-positive micrococci, mostly in pairs, but some of them in chains, were also to be seen. Pure growths of haemolytic streptococci of the pyogenes type have developed.

Opinion.-A heavy infection with haemolytic streptococci of the pyogenes type is present.

\section{Mastoidectomy on Left Ear}

This report, together with the rapid spread of the disease to the other ear, indicated the seriousness of the case. I performed a paracentesis on the left side that afternoon. Pus mixed with gas escaped under pressure, and the hissing noise made by the latter as it came away could be heard by those around. A large dose of anti-streptococcal serum was given at the same time. This was repeated on the following evening, and a third dose was administered three days later.

On January 23rd the patient's condition was worse. There was marked tenderness over the left mastoid, and on the following day I performed a mastoidectomy on the left ear. The condition found was similar to that on the right side, but much more advanced. The mucous lining of the mastoid cells had assumed a polypoid appearance, and as each cavity was opened the diseased membrane shot out like peas from a pod. The tegmen was entirely eaten through, and watery pus bathed the dura. It was necessary to expose a considerable area of the meninges to rule out an extradural abscess. The lateral sinus and bulb were also laid bare. In this case the radical operation had to be performed as the structures in the tympanic cavity were destroyed. The post-aural incision was closed and the ear drained through the meatus.

Immediately after the first operation it was noticed that the cough seemed to get worse. The sputum was blood-stained and contained pus. The report from the pathologist showed that the same organism, the haemolytic streptococcus, was present. Examination of the chest disclosed that the base of the left lung was affected, but the disease tended to be localized. This cleared up in about a fortnight, and the patient appeared to be none the worse for it. When I saw her in the first instance the left wrist was very inflamed, painful, and swollen. There was complete loss of poiver in it, and the forearm had to be kept in a sling. After the antrum was opened and drained this subsided. It is now quite normal, except for a little shooting pain at times.

Convalescence was uneventful and recovery rapid. The maxillary antrum was the only thing that caused any inconvenience. A viscid blood-stained discharge continued in spite of repeated washings and instillations of various antiseptics. I had this examined again, and it was found to contain the haemolytic streptococcus. It was only after an autogenous vaccine had been made from the discharge and a course of injections given that the antrum cleared up. The patient now enjoys perfect health, and with the exception of a slight diminution of hearing on the left side, on which the radical operation was performed, she suffered no inconvenience whatever.

A blood count was twice made. The first, immediately after the second operation, was as follows: red cells, $2,700,000$ per c.mm. ; leucocytes, 10,160 per c.mm., of which 80 per cent. were polymorphs; haemoglobin, 46 per cent. The second, taken ten days later, showed: red cells, 3,720,000 per c.mm. ; leucocytes, 8,040 per c.mm., of which 70 per cent. were polymorphs; haemoglobin, 65 per cent.

The anaesthetic given in the first operation was evipan sodium by intravenous injection, and in the second nitrous oxide and oxygen. Dr. M. Hudson administered the anaesthetic on both occasions.

I wish to thank Dr. John Oliver for his reports on the pathology of the case, and also Dr. Saxby Willis and $\mathrm{Mr}$ Buckland Jones for their advice. 